\title{
'Monopoly' Game vs. the Real World: A Teaching Tool
}

\author{
Stevie Arroyo \\ James Hoffman (New Mexico State University)
}

KEYWORDS: Entrepreneurship, Teaching Methods, economy.

Investopedia defines an entrepreneur as "an individual who creates a new business bearing most of the risks and enjoying most of the rewards." Wikipedia calls entrepreneurship "the process of designing, launching and running a new business, which is often small."

Many people got their first taste of an entrepreneurial experience when they played the Hasbro game Monopoly -- a misleading and unrealistic representation of how real-life businesses run. While it's a bad blueprint for running an actual enterprise, the game is actually a great vehicle for helping entrepreneurship teachers, students and even current business owners improve their understanding of entrepreneurship.

This article explores two questions, based on Monopoly, that are sure to provide lively discussions in the classroom and other settings and reinforce understanding of the practicalities and challenges of managing a business. We include insights and discussion points for each of the questions. We suggest that everybody involved in these discussions play the game first or at least be very familiar with how it works. Also, teachers or discussion leaders should feel free to add their own questions.

Our discussion questions are as follows:

- How does Monopoly misrepresent the real world?

- What changes could be made to Monopoly to make it more like the real world?

\section{QUESTION 1: How Does Monopoly Misrepresent the Real World?}

We already know that Monopoly misrepresents real-life entrepreneurship, but everybody will benefit by contrasting its instructions and rules with how real businesses, financing vehicles and markets operate. What follows are some specific discussion points.

\section{Ownership of Properties and Mortgages}

In a game of Monopoly, players take turns rolling a pair of dice to determine where on the board they will end up. When a player lands on an unowned property, they have the option to either buy it instantly or put it up for auction. Already, there is an issue.

Once a player lands on a property, they must pay the entirety of its value upfront in cash. This is not unrealistic, as according to Devon Thorsby for U.S. News, cash transactions made up roughly $23 \%$ of home purchases in 2018. Because paying in cash does have its advantages, doing so is completely understandable from a financial perspective. In her 2019 article for Investopedia "Getting a Mortgage vs. Paying Cash", Georgina Tzanetos points out how the lengthy process of obtaining a mortgage is circumvented, as are decades of interest rate payments. Tzanetos goes on to describe that "buying property with cash makes sense, especially if [one believes that] the market will upswing greatly in the next couple of years (Tzanetos, 2019)."

\section{Best Use of Cash}

To buy one or several properties outright, however, an investor must have a large disposable investment income. In a game of Monopoly, this issue is highlighted by the scarcity of cash, which becomes more and more relevant as the game goes on. Each player is given an initial capital of $\$ 1,500$ at the start of the game, with additional funds being generated by rental properties, passing "GO," or various unpredictable "Chance" and "Community Chest" cards.

The issue here is that cash is a rather limited resource, and with no means of maintaining a stable income, cashonly investments are not logical to pursue. Thorsby explains, "It's not wise to purchase a home with cash if you have just enough liquidity to pay for it. Cash is important to have on hand for any number of unexpected needs." In a game of Monopoly, a lack of 
cash results in players spiraling into bankruptcy, and game tokens being thrown across the room. Because players have no option to borrow over time, they are left in a scenario with fewer opportunities to diversify and a greater likelihood of running out of cash.

\section{The Monopoly Economy}

The Monopoly economy is simply not designed to maintain multiple players at once: it is designed to stomp out weaker, vulnerable players to prevent a single game from becoming a long, drawn-out affair. As a board game this works perfectly; it allows for short games with high re-playability and mass appeal. Were this not the case, it is possible that the game would not be the worldwide phenomenon that it is today.

The rather curious and restrictive way that Monopoly properties are purchased, also opens some avenues for discussion. For example, As previously mentioned, when a player lands on an un-owned property they are given the option to either buy it immediately or auction it off. To say that the property is un-owned is misleading because Monopoly properties are owned and purchased from the Bank.

\section{Foreclosed Properties}

Business Insider's 2012 article, "Monopoly Is Filled with Terrible Financial Advice," highlights the issue very well, explaining that "only foreclosed properties are purchased from banks, [as] properties are usually transferred between individual owners." Because of this, it would be fair to assume that all properties available for purchase were foreclosed at one point prior to the arrival of the player. Since there are no existing buildings or homes in any of these properties, it implies that these are either properties where the previous owners foreclosed before being able to develop, or that the Bank somehow found it more profitable to sell off whatever they could, choosing then to completely demolish any existing architecture.

Though this second point may seem like another fabrication created solely to fit a framework centered around re-playability and accessibility, it may not be without its merits. Gandel (2011) wrote a piece for Time entitled, "Bulldoze: The New Way to Foreclose," in which he explains the realities surrounding profitability in demolition during the aftermath and recovery of the Great Recession:

"Increasingly, it appears that banks are turning to demolition teams instead of realtors to rid themselves of their least-valuable repossessed homes. Last month [July 2011], Bank of America announced plans to demolish 100 foreclosed homes in the Cleveland area. The land will then be donated to local government authorities. [Bank of America] says the donations in Cleveland are part of a larger plan to rid itself of its least-salable properties, many of which, according to a company spokesperson, are worth less than $\$ 10,000 \ldots$

The banks do [these] deals because once the properties are donated, they no longer must pay taxes or for upkeep. Tax experts say the banks may also be able to get a write-off for the donations."

During this time, low-value homes were quite literally more trouble than they were worth, prompting banks to rid themselves of these foreclosed properties that were effectively a drain on potential profits.

In the world of Monopoly, a similar scenario may very well be occurring. A bank plagued by unsalable homes demolishes a series of properties, selling off what remains to the highest bidder. This scenario is quite fitting, given that according to the "official" Hasbro history, Monopoly is a game that arose from the ashes of the Great Depression.

\section{The Definition of a Monopoly Mortgage}

One glaring issue is how the game defines and treats what it calls a "mortgage." In Monopoly, those who are unfortunate enough to owe a large debt with insufficient cash may find temporary salvation in mortgaging a property back to the Bank. In doing so, the player receives $50 \%$ of the list price (the price listed on the board) but is unable to collect rent from other players who may land on that property. This is highly unusual, as it is highly common for individuals on mortgaged properties to rent out one or more homes on that property. Were the player filing for foreclosure, such an event would make more sense; the property would no longer be theirs, after all. Even then, calling this a foreclosure would be misleading, as it would imply that the property rights were always owned by the Bank and not the player that purchased it.

When a player mortgages a property in Monopoly, they obtain a specified amount, keeping the property under their name. The closest real-world equivalents revolve around the use of home equity. Often referred to as 
"second mortgages," home equity loans and home equity lines of credit (HELOCs) allow individuals to borrow against their home's equity. Home equity loans provide funds in a lump-sum with typically fixed interest rates, whereas HELOCs serve as a line of credit that people can borrow from as they see fit, with generally variable interest rates (Kurt, 2019). Of these two, the one that most closely resembles the "second mortgage" seen in Monopoly is the home equity loan, as players obtain a lump-sum specified on the Title Deed for any given property and must pay an amount later to rid themselves of the mortgage.

Unfortunately, this comparison only works on a surface level, as Monopoly has a very peculiar way of handling mortgages that is vastly different from its closest realworld equivalent. According to the official Monopoly rulebook:

"Unimproved properties can be mortgaged through the Bank at any time. Before an improved property can be mortgaged, all the buildings on all the properties of its color-group must be sold back to the Bank at half price. The mortgage value is printed on each Title Deed card."

The bottom line is that home equity cannot be borrowed against until all homes are removed. Equity may then only be borrowed on an empty property.

\section{Removal of Houses and Hotels}

There is no logical reason to require the player to remove the houses or hotels from a mortgaged property, as doing so decreases the value of the property and subsequently, the amount of equity a player can borrow against. Furthermore, the mortgage on a single property does not affect that sole property, but all other properties of the same color-group. To mortgage one property, homes on all properties of the same colorgroup must be sold back to the Bank at half price. No outside negotiation, no representation of sincere capitalism.

\section{Predatory Lending}

Unsurprisingly, the way in which Monopoly handles its mortgages, secondary or otherwise, is incredibly unique to say the least. A mortgage process such as this would likely be shut down immediately, as it demonstrates qualities similar to that of a predatory loan. According to the FDIC, "Signs of predatory lending include the lack of a fair exchange of value, or loan pricing that reaches beyond the risk that a borrower represents or other customary standards." In 2018, Will Kenton for Investopedia has described predatory lending as:

"Any unscrupulous actions carried out by a lender to entice, induce and assist a borrower in taking a loan that carries high fees, a high-interest rate, [or] strips the borrower of equity... Predatory lending benefits the lender and ignores or hinders the borrower's ability to repay a debt."

Though perhaps a more extreme form of predatory lending, Monopoly mortgages fit these criteria as they strip the borrower of equity by forcing them to sell off their homes at an unreasonably discounted price, effectively designing them as methods to ease the borrower into bankruptcy.

Recall that Monopoly is a game designed to have players bleed money until one is left standing. Mortgages serve as a clever positive feedback loop designed to remove "weaker," less financially stable players from the game faster, allowing the game to be finished in a reasonable amount of time so that it can be played again and again. With that in mind, consider the situation in which a Monopoly mortgage is generated:

- Players typically obtain a mortgage when they lack the funds to pay their debts, making it evident that they are already close to bankruptcy.

- Players are forced to sell their homes at a loss, with losses only worsening the more houses they have on the same color-group.

- With their properties mortgaged by the Bank, players become unable to collect rent, losing a valuable source of income.

Under these circumstances, it becomes evident that the role and design of mortgages in Monopoly are predatory in nature. It should then make sense that no real-world comparison truly exists, as such a mortgage system would be incredibly harmful to consumers and borrowers and would likely be classified as illegal under several state anti-predatory loan laws.

\section{Mortgage Structure}

Regardless of Monopoly's rather odd rules regarding the acquisition of a mortgage, one must also remember that there is a process for removing the mortgage as well. The rules for doing away with a mortgage are as follows: 
"In order to lift the mortgage, the owner must pay the Bank the amount of the mortgage plus 10\% interest...

However, the owner may sell this mortgaged property to another player at any agreed price. If you are the new owner, you may lift the mortgage at once if you wish by paying off the mortgage plus $10 \%$ interest to the Bank. If the mortgage is not lifted at once, you must pay the Bank $10 \%$ interest when you buy the property and if you lift the mortgage later you must pay the Bank an additional $10 \%$ interest as well as the amount of the mortgage."

It becomes difficult to apply a valid comparison to Monopoly's mortgage structures given how convoluted they become. From what has already been established, a player applies for some form of second mortgage to obtain capital, using the property (with no homes) as collateral. The property remains under the player's name, where they must later pay back the loan plus interest to the Bank.

If the player decides they no longer wish to own this property, the mortgaged property may be sold to another willing player at any negotiated price. Aly Yale explains in her 2019 article, "What Is an Assumable Mortgage?," that in the United States, mortgage transfers to another party are rather uncommon, as there is typically no benefit or incentive for the lender to do so. Only properties with "assumable mortgages" may be transferred to someone else, though these are somewhat difficult to obtain. Given this, it may be possible that Monopoly issues assumable mortgages, opting then to simply neglect labeling them as such. This idea has two problems.

The first problem is that under an assumable mortgage, the new borrower must still qualify for the loan, as lenders must see that the transfer will not affect their ability to generate revenue (Yale 2019.) If a mortgaged property is offered to another player, it can be sold to anyone at any price. This means that a player close to bankruptcy with just enough cash to cover the initial $10 \%$ charge can purchase it, despite being far from the ideal candidate for a mortgage.

The second issue revolves around the nature of the mortgage itself. Earlier it was mentioned that purchasing property in Monopoly is not done through a traditional mortgage, but through cash instead, allowing the buyer full ownership of their property. Assumable mortgages, however, are still mortgages: debt instruments that allow individuals to make monthly payments and steadily build up equity in their homes. Therefore, because the player already owns the property in question, it could not have an assumable mortgage, which implies the property was never completely the player's to begin with.

\section{Interest Rates}

One of the most fundamental concepts in the worlds of finance, business and economics are interest rates. Interest rates directly affect the cost of borrowing, and often influence the financial decisions of the corporation as well as the individual. When interest rates are low, businesses find it beneficial to raise funds through bonds, while families flock to take out loans for appliances, vehicles and homes. As interest rates rise, the dynamic flips: businesses become more hesitant to issue long-term debt, and families are more than eager to invest whatever extra cash they may have in interestpaying securities.

Though this is a rather gross oversimplification, the importance of interest rates must not be understated. That said, it is incredibly disappointing to see such a pivotal part of our financial systems absent from Hasbro's Monopoly. Throughout the entirety of the game, the concepts of interest rates are only utilized for the game's flawed mortgage structure, even then failing to capture how interest rates work.

Interest rates in Monopoly work as follows: to remove a mortgage from a property, the borrower must pay back the amount of the loan plus $10 \%$ interest. If the property is transferred to another player, the new owner must pay $10 \%$ interest upfront should they decide to remove the mortgage later. Afterwards, they must then pay an additional $10 \%$ plus the amount of the loan to remove the mortgage. Through this choice in game design, players are allowed to hold onto their mortgages as long as they deem necessary, essentially allowing them to pay interest as they see fit.

To further draw this divide between Monopoly's interest rates and their real-life counterparts, consider how these interest charges are generated. Monopoly has "fixed" interest rates that are always equal to $10 \%$ of the amount borrowed from a mortgage. It does not matter how much money the player has or what the "economic" conditions of the board are, this value will always equal $10 \%$. Real interest rates, however, are more dynamic than this. 


\section{Mortgage Interest Rates}

In 2017, Nichole Shea wrote an article for the Consumer Financial Protection Bureau entitled, "Seven factors that determine your mortgage interest rate." Before listing the seven factors, Shea notes the inherent variability of interest rates, explaining that "Interest rates, just like gasoline prices, can fluctuate from day to day and from year to year." Monopoly's interest rates, by comparison, are cemented into place and not increasing or decreasing, even if it would benefit the Bank to do so. What follows are Shea's seven factors that affect interest rates (shown in italics), with each followed by an explanation on how it relates to the world of Monopoly:

\section{Credit Scores}

"In general, consumers with higher credit scores receive lower interest rates than consumers with lower credit scores." Countless benefits come with building a good credit score, and it is without a doubt one of the most important tools any individual can develop for their financial health. It is then highly unfortunate that Monopoly does not capitalize on such an important topic. Players who have made successful payments on multiple homes or properties with plenty of disposable income will still pay the same interest as players with no properties and on the verge of bankruptcy.

\section{Home Location}

"Many lenders offer slightly different interest rates depending on what state you live in." Most properties in Monopoly (not including the railroads) are named after streets in Atlantic City, New Jersey, with the exception of Marvin Gardens, which is instead based on a neighborhood in Margate, New Jersey. Despite this, it may be safe to assume that all properties are located in a fictional New Jersey, thus making them all belong to the same state. If this is the case, this point may perhaps be rendered irrelevant for this discussion.

\section{Home Price and Loan Amount}

"Homebuyers can pay higher interest rates on loans that are particularly small or large." Properties in Monopoly range from the humble $\$ 60$ Mediterranean Avenue to the famous $\$ 400$ Boardwalk. A quick calculation of the Monopoly properties, not including railroads and utilities, shows an average price of roughly $\$ 209$, and a similar median of \$210 (see Appendix.)
Properties close to this price range include New York Avenue, Kentucky Avenue and Indiana Avenue. These three properties may be thought of as a set of "average properties," with properties above this price being considered "costly," and properties below it "economical." Were Monopoly to follow through with the stated factor, properties at extreme price ranges like Mediterranean Avenue and Boardwalk would perhaps see higher interest rates. The fact of the matter is that all properties, regardless of where they fall on the pricing spectrum, have the same flat $10 \%$ interest rate, with no increased rates being given to those on either end.

\section{Down Payment}

"In general, a larger down payment means a lower interest rate." If mortgages in Monopoly were treated like their traditional counterparts, this factor will make no sense. Monopoly mortgages are created to provide a cash loan to players so that they may pay off their debts, unlike real mortgages that allow borrowers to build equity in their homes. It makes no sense to provide a down payment on a cash loan when, presumably, the loan is being taken out to cover an initial absence of funds. With cash loans, instead of a down payment to offset potential risk, lenders use an interest rate tailored to offset the perceived risk of the borrower.

\section{Loan Term}

In general, shorter term loans have lower interest rates and lower overall costs, but higher monthly payments." Typically, interest payments for most conventional loans are paid monthly. Borrowers who miss payments may be subject to a myriad of fees, penalties, or ultimately, defaulting on the loan. Interest payments in Monopoly, however, lack any enforcement or sense of urgency regarding timely, consistent payments. Players are free to take out a mortgage once they own a property and not pay any interest for several turns. While most of Monopoly's rules are designed to treat cash as a scarce resource, the way it handles interest practically allows the player a break from the nonstop cash outflows plaguing them throughout the game. Furthermore, interest charges in Monopoly are nonrecurring, and are only paid when the player decides to lift the mortgage; in other words, towards the end of the loan's life cycle. As a result, these payments more so resemble closing costs that are often associated with traditional mortgages, and not the interest charges they claim to be. 


\section{Interest Rate Type}

“Fixed interest rates don't change over time. Adjustable rates may have an initial fixed period, after which they go up or down each period based on the market." By these definitions, the interest charges found in Monopoly loans most closely resemble fixed rates, though this is admittedly unsurprising, given that interest is typically paid once or twice, with either time offering the same $10 \%$ interest rate. Choices for adjustable-rate mortgages (ARMs) are nonexistent, forcing the player to take on fixed loans.

\section{Loan Type}

"There are several broad categories of mortgage loans, such as conventional, FHA, USDA, and VA loans... Rates can be significantly different depending on what loan type you choose." This is yet another point that is not reflected in Monopoly, which offers only one type of mortgage. Because the interest rate always remains constant despite the economic conditions of the board, it may be best to classify Monopoly mortgages as fixedrate mortgages. USDA loans may be removed from consideration, as according to the USDA.gov website, these loans are designed to provide "...low- and moderate-income households the opportunity to own adequate, modest, decent, safe and sanitary dwellings as their primary residence in eligible rural areas." VA loans may also be ruled out, as there is no clear indication in the official rulebook if the player's character has any affiliation with the military. While this last point may be deemed absurd, it is brought up as it is not uncommon for games to provide a form of "lore," or background, for their games, players, and characters that inhabit the space.

Shea's closing remarks on the subject of interest rates are as follows: "It's not just one of these factors-it's the combination-that together determine your interest rate." With so much consideration that goes into calculating interest rates, it then becomes incredibly unfortunate that Monopoly treats them with such little regard. Of these seven factors mentioned, virtually none of them are represented in the final game.

While Hasbro's Monopoly has an incredible amount of potential to teach its players about basic financial concepts, the current version of the game is much more focused on mass appeal and re-playability. The next section of this article is devoted to providing insights into what changes could be made to monopoly to make it more like the real world.

\section{QUESTION 2: Changing Monopoly to Make it More Like the Real World}

Now that we've discussed the fantasy world of Hasbro's Monopoly, we can turn to how we might change its instructions and rules to make the game more realistic. Here are some areas of discussion for Question 2.

\section{Consumer Choice}

In Monopoly, players can't control which property they land on, or how to pay for the properties. An alternative could see players having a greater degree of control over where they move in exchange for cash. For example, players could choose to move four spaces on a board and pay $\$ 40$ ( $\$ 10$ for each space.) Alternatively, dice rolls could remain a part of the gameplay and simply be adjusted to achieve the desired roll. If a player wants to move five spaces and rolls a seven, they could make up the difference and pay $\$ 100$ for each adjusted space.

\section{Properties and Mortgages}

Assume that properties available for sale have a dwelling on site, and that costs for additional houses will instead be substituted for "expansions," as it makes more sense to expand on an already existing home than to create an additional building or buildings on that property. Regarding the purchase of properties, rather than be forced to buy properties outright, players should be given the option to take out a mortgage. This would not only reflect a more realistic approach to real estate investment, but it would also allow for a deeper layer of strategy, as players decide what option benefits them the most. In addition to this, mortgaged properties would still allow players to collect rent. Players could provide a specified down payment on the turn when they buy the property, and then proceed to make payments for a specified amount of turns. Payments would be timed at the end of a player's turn, reflecting payments towards both the principal and interest.

\section{Credit Scores}

Those players with a high net worth and/or who successfully paid off one or more mortgages will have a higher credit score. A potential formula for determining a player's credit score is as follows: 
Credit Score $=(11 * \sqrt{\text { Net Worth }+1000})+(10 * \#$ of Successful Mortgages $)$

It is important to remember, however, that this is a board game that should be approachable by younger players. As a result, a simpler method to derive a credit score could simply use a table such as this:

Net Worth

$\$ 0$ - $\$ 299$

$\$ 300-\$ 699$

$\$ 700-\$ 1,299$

$\$ 1,300-\$ 2,199$

$\$ 2,200-\$ 3,999$

$\$ 4,000+$

To simplify the process, each property may have its own base interest rate printed on the title deed. This base rate derives its value from Nichole Shea's interest concept of "Home Price and Loan Amount." Recall that loans that are particularly high or low can see higher interest rates (Shea, 2017). Mortgages near the highest and lowest amounts would have a higher base interest rate than properties closer to the average or median amount. The interest payment amount could then be determined by a combination of the down payment, the "length" of the mortgage, the player's credit score, the type of mortgage, and the economic conditions of the board. By allowing for variations in interest rates, this fundamental concept is then able to have a more active and dynamic role in the game. Below are the possible factors and amounts that may affect the final interest rate:
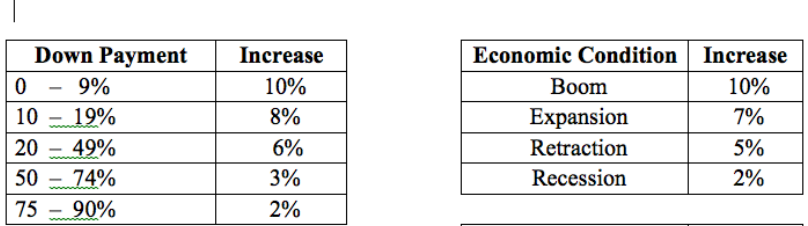

\begin{tabular}{|c|c|}
\hline $\begin{array}{c}\text { Turns Until } \\
\text { Payoff }\end{array}$ & Increase \\
\hline 4 & $10 \%$ \\
\hline 3 & $8 \%$ \\
\hline 2 & $4 \%$ \\
\hline 1 & $2 \%$ \\
\hline
\end{tabular}

\begin{tabular}{|c|c|}
\hline Credit Score & Increase \\
\hline 300 & $10 \%$ \\
\hline 400 & $9 \%$ \\
\hline 500 & $8 \%$ \\
\hline 600 & $6 \%$ \\
\hline 700 & $4 \%$ \\
\hline 800 & $2 \%$ \\
\hline \multicolumn{2}{|c}{} \\
\hline
\end{tabular}

\section{Economic Conditions}

Variations in the economic conditions can be implemented in a variety of ways based on randomization. In this example, at the start of the game and before each new turn cycle (before all players undergo their turn) a card must be drawn from a deck. Five different cards could be drawn: Economic Boom, Economic Expansion, Economic Retraction, Economic Recession, and Continue Cycle. These first four items are designed to mimic the four stages of the business cycle, with each issuing an appropriate effect onto the game board. An Economic Boom, for example, greatly increases mortgage interest rates, as well as the amount of expenses such as rent to other players, and payments demanded by Community Chest and Chance cards. Continue Cycle prolongs the state of the current cycle for another turn. This is done to prevent a sort of rollercoaster economy that constantly fluctuates between booms and recessions. Furthermore, having a "buffer" between cycles mimics the uncertainty of when the next cycle will occur.

\section{Passage of Time}

Once all players have completed their turn, this marks the beginning of a new turn cycle. Each turn cycle represents the passage of time, with a full year completed at the end of the 12th turn cycle. At the start of each new turn cycle, the player who goes first draws an Economic Condition card before initiating their turn. Mortgage payments, if owed, must be made once every turn cycle, otherwise the property will be foreclosed and auctioned. Salaries are distributed at the start of each fourth turn cycle, and taxes must be paid first at the start of the $13^{\text {th }}$ turn cycle.

\section{Conclusion}

Although Monopoly glamorizes the idea of hardcore capitalism, it accomplishes this by neglecting various 
financial principles that it should perhaps hold closer to heart. Consumer choice from the individual player is nowhere to be found, as the choice is instead passed on to a set of dice that effectively decides which properties a player may buy. While real financial endeavors have a high degree of strategy and planning, with a shred of luck involved, Monopoly foregoes these first two items, opting instead to focus heavily on luck-based game play. Ironically, because of these and other limitations, Monopoly provides an excellent vehicle to discuss several business principles in an entrepreneurial setting.

\section{References}

Federal Deposit Insurance Corporation. (2007, January 22). "FDIC's Supervisory

Policy on Predatory Lending." Retrieved from https://www.fdic.gov/news/news/financial/2007/fil07006 a.html

Federal Reserve Bank of St. Louis. (n.d.). "How Monetary Policy Works."

Gad, S. (2019, June 25). "5 Lessons in Finance and Investing From Monopoly." Investopedia.

Gandel, S. (2011, August 1). "Bulldoze: The New Way to Foreclose." Time. Retrieved from http://business.time.com/2011/08/01/bulldoze-the-newway-to-foreclose/

Hayes, A. (2020, January, 28). "Entrepreneur." Investopedia. Retrieved from https://www.investopedia.com/terms/e/entrepreneur.asp

Kenton, W. (2018, March 26). "Predatory Lending." Investopedia. Retrieved from https://www.investopedia.com/terms/p/predatory_lendin g.asp

Kenton, W. (2018, April 23). "Horizontal Acquisition." Investopedia. Retrieved from https://www.investopedia.com/terms/h/horizontalacquisition.asp

Kurt, D. (2019, August 17). "Home Equity Loans and Home Equity Lines of Credit - HELOC." Investopedia. Retrieved from https://www.investopedia.com/mortgage/heloc/

Monopoly: Parker Brothers Real Estate Trading Game. (n.d.). Parker Brothers. Retrieved from https://www.hasbro.com/common/instruct/monins.pdf

Monopoly Game: Cheaters Edition. (n.d.). Hasbro.

Monopoly is Filled with Terrible Financial Advice. (2012, November 8). Investopedia.

Pilon, M. (2015, January). "Monopoly Was Designed to Teach the 99\% About Income Inequality." Smithsonian. Retrieved from https://www.smithsonianmag.com/arts-c ulture/monopoly-was-designed-teach-99-about-incomeinequality-180953630/

Shea, N. (2017, September 29). "Seven factors that determine your mortgage interest rate." Consumer Financial Protection Bureau. Retrieved from https://www.consumerfinance.gov/about-us/blog/7-facto rs-determine-your-mortgage-interest-rate/

The Sherman Antitrust Act of 1890. (n.d.). Fundamental Finance. Retrieved from http://economics.fundamentalfinance.com/shermanact.php

Thorsby, D. (2018, November 30). "Reasons Not to Buy Your House With Cash.” U.S. News.

Tzanetos, G. (2019, July 28). "Getting a Mortgage vs. Paying Cash: What's the Difference?" Investopedia. Retrieved from https://www.investopedia.com/articles/investing/111116 /getting-mortgage-vs-paying-cash-investmentproperties.asp

United States Courts. (n.d.). "Chapter 7 - Bankruptcy Basics." Retrieved from https://www.uscourts.gov/services-forms/bankruptcy/ba nkruptcy-basics/chapter-7-bankruptcy-basics

United States Department of Labor. (n.d.). "Back Pay." Retrieved from https://www.dol.gov/general/topic/wages/backpay

United States Department of the Treasury. (n.d.). "Roles of the Treasury." Retrieved from https://home.treasury.gov/about/general-information/roleof-the-treasury

Wikipedia. (2020, February 15). "Entrepreneurship." Retrieved from https://en.wikipedia.org/wiki/Entrepreneurship . 
Yale A. J. (2019, July 22). "What Is an Assumable Mortgage?" The Balance. Retrieved from https://www.thebalance.com/what-is-an-assumablemortgage-4693607 